\title{
Malunion of Bone
}

National Cancer Institute

\section{Source}

National Cancer Institute. Malunion of Bone. NCI Thesaurus. Code C118393.

Faulty healing of bone, resulting in improper anatomical alignment. 